Vol. 24, No. 1, Januari 2021, hlm. 99-111

p-ISSN: 1410-9344; e-ISSN: 2549-5631

WARTA LPM

homepage: http://journals.ums.ac.id/index.php/warta

\title{
Penataan Visual Signage Koridor Jalan Bunga Ejaya Kelurahan Bontoala Tua Kecamatan Bontoala Kota Makassar
}

\author{
Citra Amalia Amal ${ }^{1}$, Andi Annisa Amalia ${ }^{2}$ \\ Prodi Arsitektur Universitas Muhammadiyah Makassar \\ Email: ${ }^{1}$ citraamaliaamal@unismuh.ac.id, 2annisa@unismuh.ac.id
}

\begin{tabular}{l} 
Article Info \\
\hline \multicolumn{1}{c}{ Submitted: 11 May 2020} \\
Revised: 6 July 2020 \\
Accepted: 16 November 2020 \\
Published: 12 December 2020 \\
Keywords : Corridor nodes, \\
Identity, Signage, Arabic \\
Cemeteries, Islamic
\end{tabular}

Kata Kunci : Node koridor, Identitas, Signage, Pemakaman Arab, Islami.

\begin{abstract}
Bontoala Tua Village is an old city area of Makassar which marks the development period of Islam in Makassar City. One of the historical evidence of the development of Islam in this place, the Sayye (Arabic) Cemetery Complex, Lajangiru Tomb and Ejaya Flower Tomb located on Jalan Bunga Ejaya. However, the linkage corridor to the place has not been arranged properly, at the connecting corridor node to the location there is no information board or signage making it difficult for visitors or pilgrims because there is no location identity as a marker leading to the burial location. Whereas the nodes and nodes of the lane leading to this place are the linkage connecting the main corridors of the city such as Jalan Veteran and Jalan Masjid Raya Makassar. The purpose of community service activities is to design and create signage of the Arabic Cemetery on Jalan Bunga Ejaya that meets the elements of visibility (visible), legibility (readable) and visual aspects (aesthetic). The method of implementing the activity is participatory approach, ground survey, discussion and design. Stages of activities carried out consisted of socialization, field surveys, discussion of concepts, preparation of tools and materials as well as assembly and installation of the Arab Bontoala Cemetery signage. Signage that is implemented in Jalan Bunga Ejaya Corridor is a type of free standing sign which is a signpost element to the location of the Arab Bontoala Cemetery. This signage has an Islamic concept with a visual display of green, simple, lightweight, simple and the shape of the pillar is integrated with the information board that is placed at the node of Jalan Bunga Ejaya with Jalan Lamuru.
\end{abstract}

Abstrak
Kelurahan Bontoala Tua merupakan kawasan Kota lama Makassar
yang menandai masa perkembangan agama Islam di Kota Makassar.
Salah satu bukti sejarah perkembangan Islam di tempat ini, adanya
Kompleks Pemakaman Sayye (Arab) yaitu Makam Lajangiru dan
Makam Bunga Ejaya yang terletak di Jalan Bunga Ejaya. Namun koridor
linkage menuju tempat tersebut belum tertata dengan baik, pada node


koridor penghubung menuju lokasi tidak terdapat papan informasi atau signage sehingga menyulitkan pengunjung atau peziarah karena belum ada identitas lokasi sebagai penanda menuju ke lokasi pemakaman tersebut. Padahal node dan simpul-simpul jalur menuju tempat tersebut merupakan linkage penghubung koridor utama Kota seperti Jalan Veteran dan Jalan Masjid Raya Makassar. Tujuan kegiatan pengabdian masyarakat adalah mendesain dan membuat signage Pemakaman Arab di Jalan Bunga Ejaya yang memenuhi unsur visibilitas (terlihat), legibilitas (terbaca), dan aspek visual (estetika). Metode yang digunakan dalam kegiatan penataan visual signage ini adalah metode participatory approach (pendekatan semi partisipatif). Tahapan kegiatan yang dilakukan terdiri dari sosialisasi, survei lapangan, diskusi konsep, persiapan alat dan bahan serta perakitan, dan pemasangan signage Pemakaman Arab Bontoala. Signage yang diimplementasikan pada Koridor Jalan Bunga Ejaya adalah jenis free standing sign merupakan elemen penunjuk arah ke lokasi Pemakaman Arab Bontoala. Signage ini berkonsep Islami dengan tampilan visual warna hijau, simpel, ringan, sederhana, dan bentuk tiang menyatu dengan papan informasinya yang ditempatkan pada node Jalan Bunga Ejaya dengan Jalan Lamuru.

\section{PENDAHULUAN}

Kelurahan Bontoala Tua yang terletak di bagian barat pusat Kota Makassar memiliki batas-batas administratif sebagai berikut: di sebelah utara berbatasan dengan Kelurahan Bunga Ejaya, sebelah selatan berbatasan dengan Kelurahan Bontoala, sebelah timur berbatasan dengan Kelurahan Baraya dan sebelah barat berbatasan dengan Kecamatan Bontoala. Luas permukiman adalah 10,59 $\mathrm{Ha}$, secara administrasi terbagi dalam 5 wilayah RW dan 24 RT. Bontoala Tua merupakan kawasan Kota lama Makassar yang menandai perkembangan agama Islam di Kota Makassar. Pada tempat ini terdapat Pemakaman Sayye' (Arab). Adapun Pemakaman tersebut berada pada koridor utama Jalan Bunga Ejaya, titik lokasi dapat dilihat pada Gambar 1.

Masuknya agama Islam penduduk pribumi nusantara serta terbentuknya pemerintahan Islam di berbagai daerah kepulauan termasuk di Sulawesi Selatan. Orang Arab yang bermigrasi ke nusantara juga semakin banyak, yang terbesar diantaranya adalah berasal dari Hadramaut, Yaman. Migrasi ini bahkan terbesar sepanjang Hadramaut. Salah satu bukti adanya kedatangan orang Arab pada masa itu adalah ditemukan makam atau kompleks makam orang Arab yang diketahui oleh masyarakat sekitarnya atau dapat dikenal melalui inskripsi di dalamnya (Zubair, 2011). Disebutkan pula bahwa di Sulawesi Selatan terdapat kompleks makam besar milik penyiar agama Islam ratusan tahun silam yang bangunannya berbentuk kubah masjid dan tempat ini secara turun temurun dikenal dengan kompleks pemakaman orang Arab.

Di Kecamatan Bontoala, Kota Makassar, Provinsi Sulawesi Selatan terdapat sebuah situs berupa kompleks makam yang disebut Makam Lajangiru di mana di tempat tersebut terdapat lima makam besar yang bangunannya berbentuk kubah masjid, mereka yang dimakamkan di tempat tersebut adalah Penyiar Agama Islam ratusan tahun silam. Masyarakat setempat sering menyebut tempat ini sebagai Pemakaman Arab. Keberadaan dan akses menuju Pemakaman Arab di Bontoala Tua tidak mudah diketahui karena secara visual belum ada penanda atau signage menuju ke lokasi tersebut. Padahal umumnya, signage sebagai elemen visual dominan pada suatu koridor dan memiliki peran penting dalam memberikan informasi dan gambaran figure ground yang ada pada suatu tempat.

Koridor Jalan Bunga Ejaya (lihat Gambar 1) merupakan akses utama menuju Pemakaman Arab Bontoala, kawasan Kota lama dengan fungsi guna lahan sebagai permukiman dan 
perdagangan jasa. Sepanjang koridor terdapat tata informasi tetapi terbatas berupa papan nama jalan, papan reklame took, dan usaha jasa lainnya. Belum adanya penataan pemasangan mengakibatkan koridor ini terkesan tidak teratur, khususnya jika dilihat dari tampilan visual signage yang ada baik secara desain maupun perletakan menyebabkan pencemaran visual. Keberadaan signage di Kelurahan Bontoala Tua terutama main entrance koridor yang menuju ke kawasan Pekuburan Arab kurang mendapat perhatian. Belum ada identitas kawasan Bunga Ejaya, belum adanya papan informasi pada node koridor Jalan Bunga Ejaya dan Jalan Tinumbu yang menandakan akses menuju Pemakaman Arab atau dengan kata lain dari aspek estetika belum adanya signage kawasan yang bernilai arsitektur Islam dan mencirikan eksistensinya sebagai kawasan wisata ziarah Pekuburan Arab/ Sayye'.

Sistem tata informasi dalam urban design disebut signage system berfungsi untuk mempermudah pejalan kaki mengenal fungsi bangunan, penempatannya tidak boleh menghalangi bukaan bangunan dan tidak mengurangi jalur minimum pejalan kaki sebesar 2 meter (Nasruddin \& Marpaung, 2018). Selain itu, perancangan signage dan media interaktif seharusnya sudah terintegrasi branding tempat (Hanifunisa \& Swasty, 2020). Signage menurut Gibson (2009) merupakan objek yang memberikan arahan dan membantu manusia dalam menavigasi ruang atau tempat, arahan dan sarana informasi untuk kenyamanan di lokasi, dan dapat menjadi sarana efektif dalam membangun dan mengembangkan sebuah brand. Ketiadaan sistem penunjuk arah (wayfinding system) terbukti mampu menimbulkan ketidakteraturan dalam penataan ruas jalan kendaraan, pejalan kaki hingga kebutuhan penanda toko dan bangunan fungsional lainnya (Prastomo, 2018). Lebih lanjut dikatakan bahwa konsep visibilitas identitas baik lingkungan terbuka maupun facade bangunan dapat dipertimbangkan dalam ukuran yang mudah dilihat dan dimengerti peziarah, baik oleh peziarah yang menggunakan kendaraan bermotor maupun berjalan kaki. Sistem penanda atau sistem informasi merupakan keharusan suatu tempat untuk mendapatkan informasi yang cepat dan jelas yang dikemas secara menarik dan memberikan nilai tambah dengan strategi memvisualisasikan keunikan kawasan, menyenangkan, diinspirasi dari alam, dan tidak membosankan (Ahmad, 2013).

Perancangan signage untuk perletakan baik secara dua dimensional maupun tiga dimensional perlu mendapatkan perhatian khusus (Wijayanti, 2019). Menurut Puspitasari dan Darmawan (2013), signage tidak sebatas diartikan sebagai tanda, tetapi lebih kepada tema suatu area yang dirancang untuk menginformasikan tempat dan arah baik dalam lingkup interior maupun eksterior. Lebih lanjut dinyatakan juga bahwa setiap sudut pandang atau persepsi dari pengguna jalan dan tanggapannya terhadap keberadaan signage dikondisikan oleh karakteristik khusus manusia, karena faktor manusia memegang peranan penting dalam memperoleh solusi terbaik yang merupakan 'good design solution' bagi masyarakat pengguna.

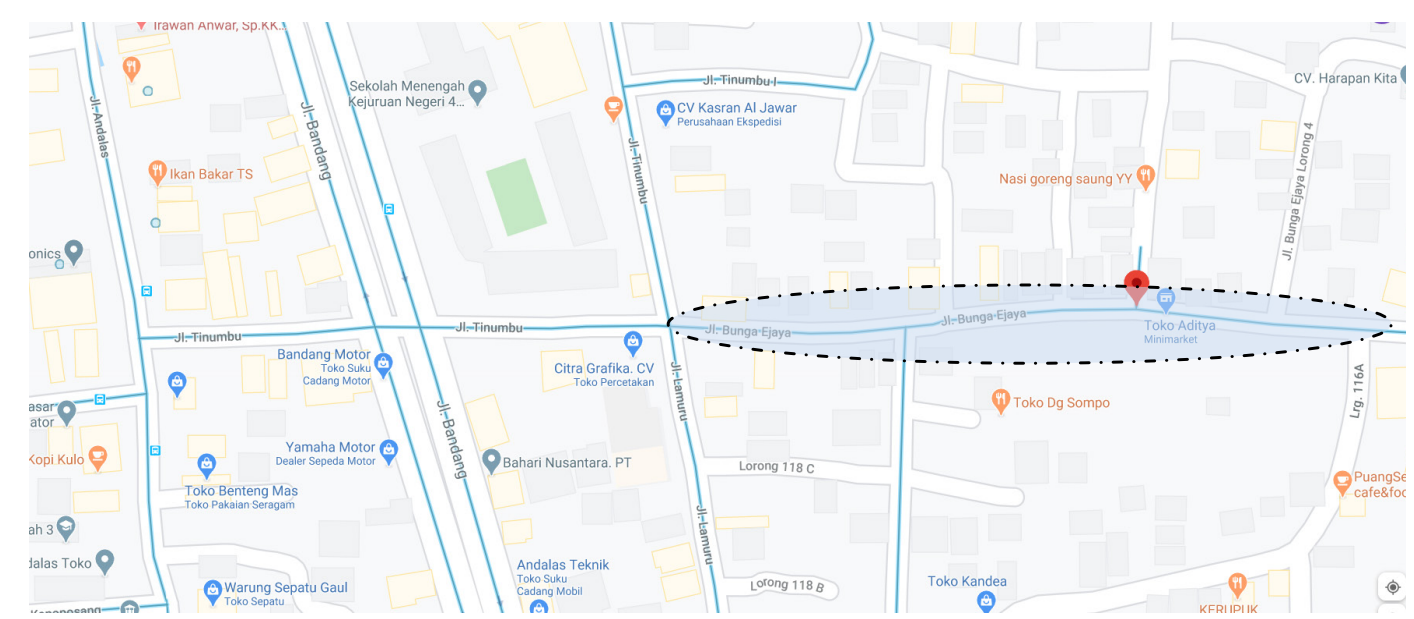

Gambar 1. Peta Lokasi dan Koridor Jalan Bunga Ejaya sebagai Akses Utama ke Area Pekuburan Arab 
Tata informasi atau dengan kata lain sign system merupakan bentuk informasi dan orientasi kota yang dirancang khusus sebagai elemen perkotaan. Dengan demikian, penataan tata informasi sangat diperlukan untuk mencapai keseragaman bentuk, tampilan visual koridor yang menarik dan estetika, serta memudahkan penyampaian informasi bagi para pejalan kaki dan pengemudi kendaraan bermotor. Nasruddin \& Marpaung (2018) menyatakan bahwa agar tidak terjadi kesemrawutan maka diperlukan pengaturan dan penempatan baik dari ukuran, ketinggian, dan luasan seperti papan nama toko tidak lebih dari 15\% luasan dinding, papan reklame hanya boleh diletakkan pada lantai dua, papan iklan layanan masyarakat wajib memiliki izin dari pemerintah setempat, papan nama neon box dengan luas maksimal 1,2 meter persegi dengan ketinggian 2 meter dari atas tanah dan untuk papan reklame bagian sisi panelnya tidak boleh menjorok ke badan jalan.

Dari teori-teori di atas dapat disimpulkan bahwa signage adalah elemen fisik urban design yang berfungsi sebagai navigasi, menginformasikan tempat, arah, dan identitas ruang secara visual.

Di sisi lain, tingginya jumlah peziarah yang datang berkunjung ke Pemakaman Arab Bontoala sebagai salah satu makam tertua yang mengiringi perkembangan agama Islam di Kota Makassar ini juga menjadi pertimbangan perlunya dibuat signage. Dalam wawancara kami kepada juru kunci Pemakaman Arab Bontoala dapat disimpulkan bahwa secara regular, pengunjung harian berjumlah belasan, dan mencapai puluhan jumlah pengunjung khususnya di hari Jumat, weekend, maupun hari libur nasional, serta sebelum memasuki bulan Ramadan. Pada hari-hari besar keagamaan misalnya Hari Raya Idulfitri dan Iduladha, peziarah Pekuburan Arab dapat mencapai jumlah ratusan lintas gender dan usia. Bahkan, mantan Wakil Presiden Republik Indonesia Bapak Muhammad Jusuf Kalla secara periodik datang berziarah ke makam orang tuanya yang berada di kompleks pekuburan ini. Karena pentingnya keberadaan signage maka diperlukan perancangan dan pembuatan signage pada Jalan Bunga Ejaya berupa tanda petunjuk arah Pemakaman Arab Bontoala (lihat Gambar 3). Lokasi perletakannya pada node Jalan Bunga Ejaya dengan Jalan Tinumbu dan Jalan Lamuru yang ditempatkan pada area zona pejalan kaki yang dirancang berbentuk persegi empat (lihat Gambar 2) dimana bentuk persegi empat efektif untuk tanda yang berisi informasi. Pendekatan yang digunakan dalam mendesain signage yaitu pertama disesuaikan dengan kondisi lingkungan sekitar, dipertimbangkan agar menjadi satu kesatuan dengan elemenelemen yang sudah ada, karena suatu signage harus memenuhi aspek fungsional dan estetika. Tujuan kegiatan pengabdian masyarakat ini adalah untuk merancang dan membuat signage yang akan dipasang pada node koridor Jalan Bunga Ejaya. Manfaat kegiatan pengabdian ini adalah terbentuknya struktur visual koridor jalan serta terciptanya citra lingkungan dengan menghidupkan street space dengan adanya signage Pemakaman Arab Bontoala.

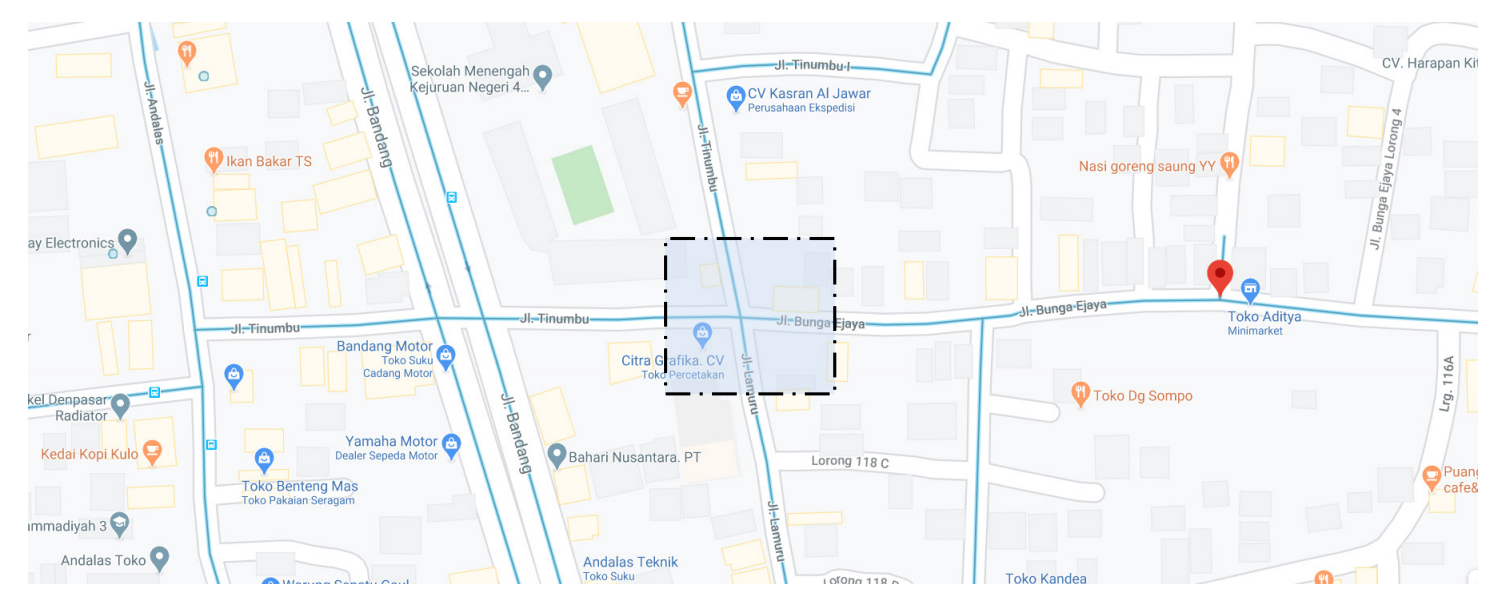

Gambar 2. Node Berbentuk Segi Empat yang Terbentuk dari Pertemuan Jalan Bunga Ejaya, Jalan Lamuru, dan Jalan Tinumbu 

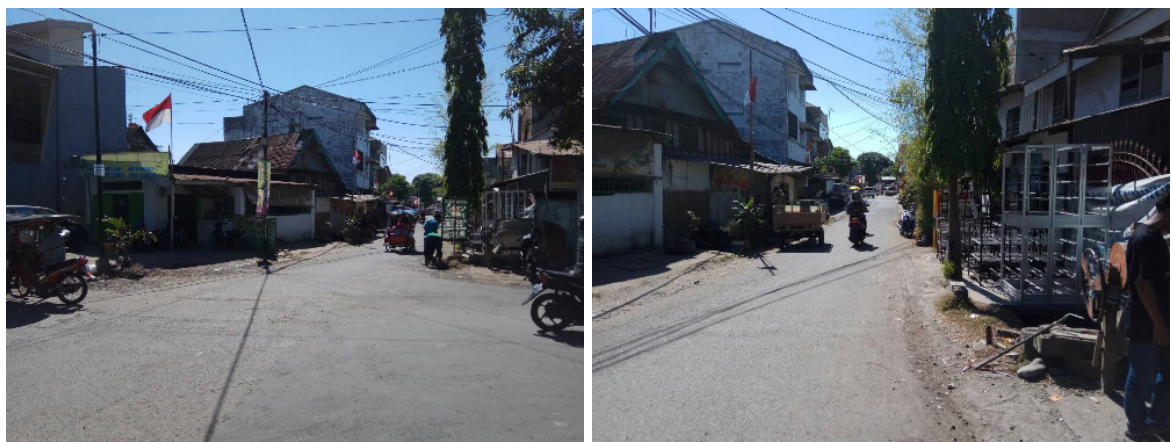

Gambar 3. Belum Terdapat Penunjuk Arah ke Pemakaman Arab Bontoala

Dengan adanya desain signage yang memperhatikan unsur visibilitas (terlihat), legibilitas (terbaca) dan aspek visual (estetika) di koridor Jalan Bunga Ejaya diharapkan dapat berfungsi sebagai informasi petunjuk arah dan menjadi nilai tambah visual koridor sebagai akses utama Pemakaman Arab Bontoala yang memperkuat eksistensinya sebagai Kawasan Wisata Ziarah.

\section{METODE}

Metode yang digunakan dalam kegiatan penataan visual signage ini adalah metode participatory approach (pendekatan semi partisipatif) yaitu dengan melibatkan tokoh kunci seperti tokoh masyarakat yang berpengaruh dan dituakan di sekitar lokasi Pemakaman Arab Bontoala, Ketua RT dan RW, serta masyarakat setempat yang terdiri atas masyarakat yang tinggal di sepanjang koridor Jalan Bunga Ejaya serta masyarakat yang bermukim di sekitar kompleks pemakaman. Hasil dari pendekatan ini menjadi landasan untuk menentukan lokasi spot/titik signage, bentuk desain signage yang akan digunakan yaitu dengan pendekatan nuansa Islami, kegiatan pembuatan dan pemasangan signage.

Pada tahap awal, Tim Pelaksana Pengabdian mengajak tokoh masyarakat menemukenali identitas lingkungannya melalui survei awal yaitu survei bersama tokoh masyarakat di koridor Jalan Bunga Ejaya dan Jalan Tinumbu pada path yang menghubungkan ke Pemakaman Arab Bontoala. Pada tahapan survey tersebut, dibuat sketsa rencana titik peletakan elemen.

Tahap selanjutnya adalah pelaksanaan kegiatan pengabdian meliputi sosialisasi maksud, denganpemaparandaritimpengabdianmengenai tujuan dan metode pelaksanaan kegiatan. Kemudian dilanjutkan dengan pemaparan teori yang berkaitan dengan peran dan fungsi signage, tipologi, serta jenis dan manfaatnya dan seperti apa partisipasi masyarakat dalam pelaksanaan kegiatan. Kemudian peserta juga memaparkan

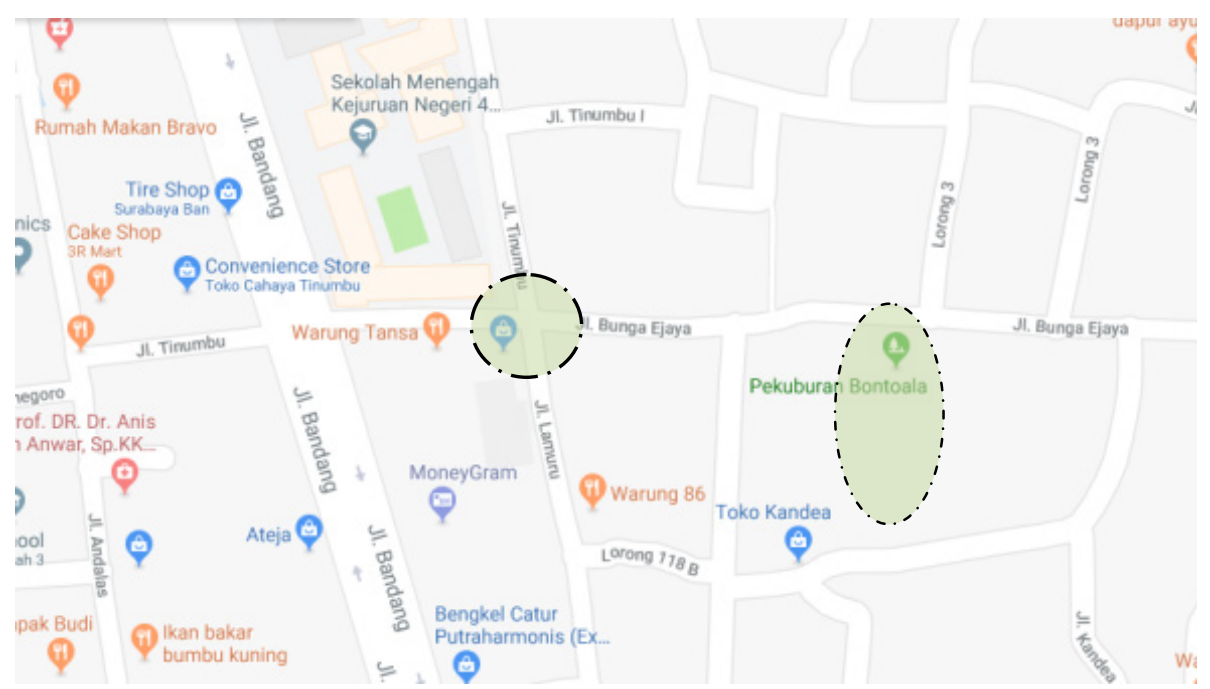

Gambar 4. Titik/Spot Perletakan Signage Berada pada Pangkal Jalan Bunga Ejaya 


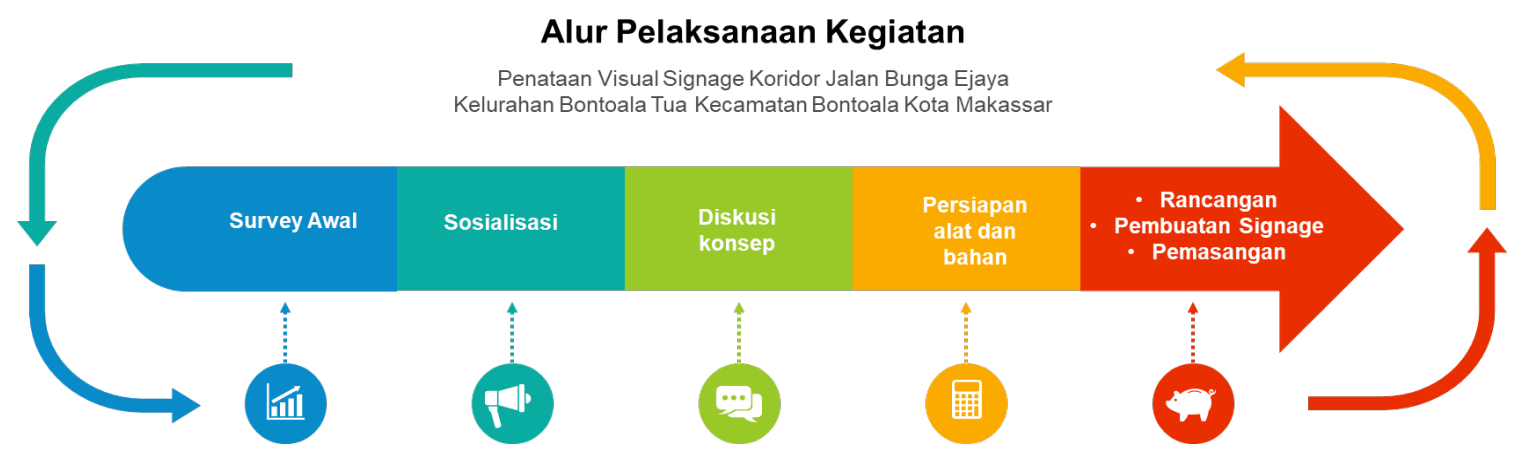

Gambar 5. Diagram Alur Pelaksanaan Kegiatan

permasalahan elemen jalan berdasarkan hasil survei awal. Selanjutnya dilakukan diskusi persiapan untuk tahapan selanjutnya.

Setelah tahap sosialisasi, disusun konsep desain yang nantinya menyepakati rancangan desain signage, termasuk item informasi yang akan tertuang dalam desain signage tersebut. Tahapan ini berlangsung selama dua hari.

Setelah konsep desain selesai, maka tahapan berikutnya adalah pembuatan visual signage pada titik lokasi yang telah disepakati dengan desain signage bernuansa warna hijau dan identik dengan nuansa Islami, bertuliskan arah dan jarak ke Pemakaman Arab Bontoala. Tahapan akhir adalah pemasangan signage, dilakukan bersama-sama dengan masyarakat dan Ketua RT setempat. Prioritas dalam mendesain signage harus menyampaikan pesan komunikatif dan informatif sehingga signage bersifat lebih informatif daripada dekoratif (Situmorang \& Swasty, 2016). Tahapan pembuatan dan pemasangan signage ini berlangsung selama tiga hari.

\section{HASIL DAN PEMBAHASAN}

\section{Tahap Survei Awal}

Tahap survei awal dilakukan bersama beberapa tokoh masyarakat yang ada di sekitar kawasan Pemakaman Arab Bontoala baik Ketua RT, Ketua RW, dan pihak pengelola pemakaman. Survei awal dilakukan dengan menelusuri dan mengidentifikasi elemen fisik pada koridor jalan Bunga Ejaya, Jalan Tinumbu dan Jalan Lamuru. Hasil identifikasi dibuat pada kertas sketsa dan dilengkapi dengan dokumentasi titik-titik perletakan elemen furniture jalan. Survei awal menunjukkan bahwa belum ada elemen furniture jalan berupa apapun yang menjadi penanda sepanjang koridor jalan menuju Pekuburan Arab Bontoala (Gambar 6). Tim Pelaksana Pengabdian memberi masukan agar sebaiknya titik/spot perletakan signage berada pada area yang berbentuk segi empat dengan mempertimbangkan keefektifitasan pembacaaan signage oleh pengguna jalan, serta letaknya yang berada pada akses utama Kawasan Pekuburan Arab.

\section{Tahap Sosialisasi}

Tahap sosialisasi dilakukan dengan pemaparan Ketua Tim Pengabdi kepada peserta mengenai maksud dan tujuan dilakukannya pengabdian masyarakat dari Universitas Muhammadiyah Makassar, serta metode pelaksanaan kegiatan yang akan dilakukan. Selanjutnya pemaparan dilakukan juga oleh anggota tim pengabdian menjelaskan peran dan fungsi signage di koridor jalan, dan partisipasi masyarakat dalam pelaksanaan kegiatan pengabdian. Pada tahap sosialisasi ini dihadiri oleh 15 orang peserta terdiri dari

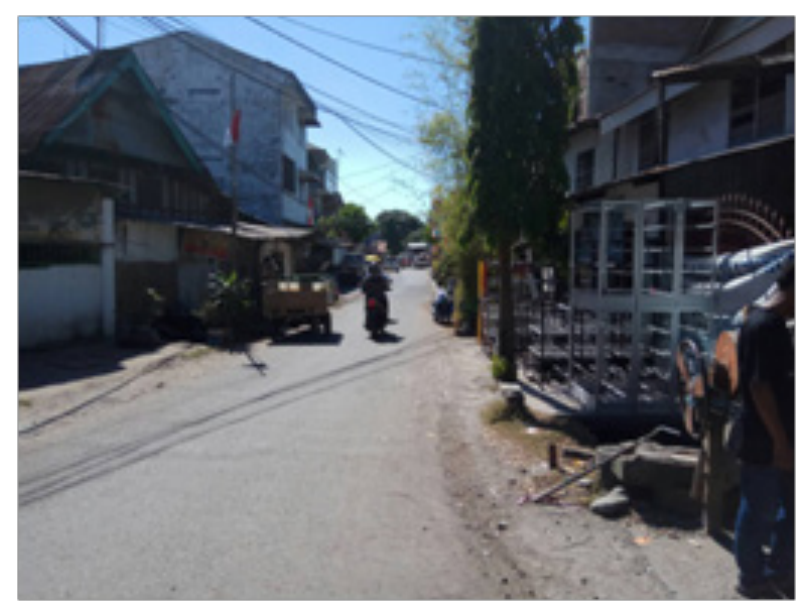

Gambar 6. Survei Awal Kondisi Koridor Jalan Bunga Ejaya 
Ketua RT, Ketua RW, dan warga masyarakat yang bertempat tinggal di Jalan Bunga Ejaya dan sekitar Pemakaman Arab Bontoala. Ketua RT memberikan sambutan kepada peserta dan membahas rangkaian kegiatan yang akan dilakukan dan yang telah dilaksanakan sebelumnya pada tahapan survei awal.

Pada sosialisasi ini Tim Pengabdian memberikan penjelasan kepada peserta tipologi signage dan jenis-jenisnya serta manfaatnya terhadap lingkungan. Pada tahap sosialisasi tersebut Ketua RT menyampaikan juga beberapa permasalahan elemen pada koridor Jalan Bunga Ejaya, Jalan Tinumbu, dan Jalan Lamuru. Kemudian dilakukan juga diskusi tahapan selanjutnya dan langkahlangkah persiapan. Hasil diskusi disepakati lokasi pemasangan signage yaitu berada di node antara Jalan Tinumbu, Lamuru, dan Bunga Ejaya yang merupakan koridor utama menuju PemakamanArab/Sayye'. Pertimbangan peserta perletakan pada node jalan karena merupakan simpul strategis di mana aktivitas saling bertemu dan titik pergerakan ke segala arah, sehingga dapat terlihat dari beberapa arah jalan. Selain itu bila signage ditempatkan pada node jalan, maka pengamat yang melalui jalan tersebut bisa merasakan masuk ke distrik Pemakaman Arab Bontoala. Posisi penempatan signage di ujung Jalan Bunga Ejaya yang berorientasi ke Jalan Bunga Lamuru dan Jalan Tinumbu.

\section{Tahap Penyusunan Konsep Desain}

Konsep penataan signage sebagai decision point perlu memperhatikan sudut pandang user secara vertikal, penggunaannya sign hybrid harus dihindari lebih menggunakan sign jenis grafis untuk efektivitas pemberian informasi pada pengujung sesuai kebutuhan (Taufiq \& Wulandari, 2016).

Tahap penyusunan konsep desain melalui metode participatory approach (pendekatan partisipatif) dengan melakukan diskusi dengan tokoh masyarakat untuk menentukan desain visual signage yang sesuai dengan identitas lingkungan. Metode ini digunakan karena tokoh masyarakat dianggap sebagai salah satu pengguna jalan dan berdomisili di lokasi, di mana setiap sudut pandang atau persepsi dari pengguna jalan dan tanggapannya terhadap signage dikondisikan oleh karakteristik khusus manusia, baik secara biophysics-pshyche, socioculture, spiritual cosmologis transcendental dengan kelima inderanya (Puspitasari \& Darmawan, 2013). Lebih lanjut dikatakan bahwa faktor manusia sebagai pengguna memegang peranan penting dalam memperoleh solusi terbaik yang merupakan 'good solution' bagi masyarakat pengguna signage tersebut.

Penyusunan konsep diawali dengan pemaparan signage dari sisi historis, penggalian tema yang konsisten dan sesuai dengan tempat yang akan dibuatkan signage informasinya, tujuan pembuatannya, penggunaannya, standar grafis, material, dan penempatannya. Dalam pemaparan tersebut dijabarkan bahwa awalnya sejarah signage bermula dari banyak desainer wayfinding yang merupakan orangorang kelahiran masa perang dunia II, dimana mereka mengalami kondisi politik, lingkungan,

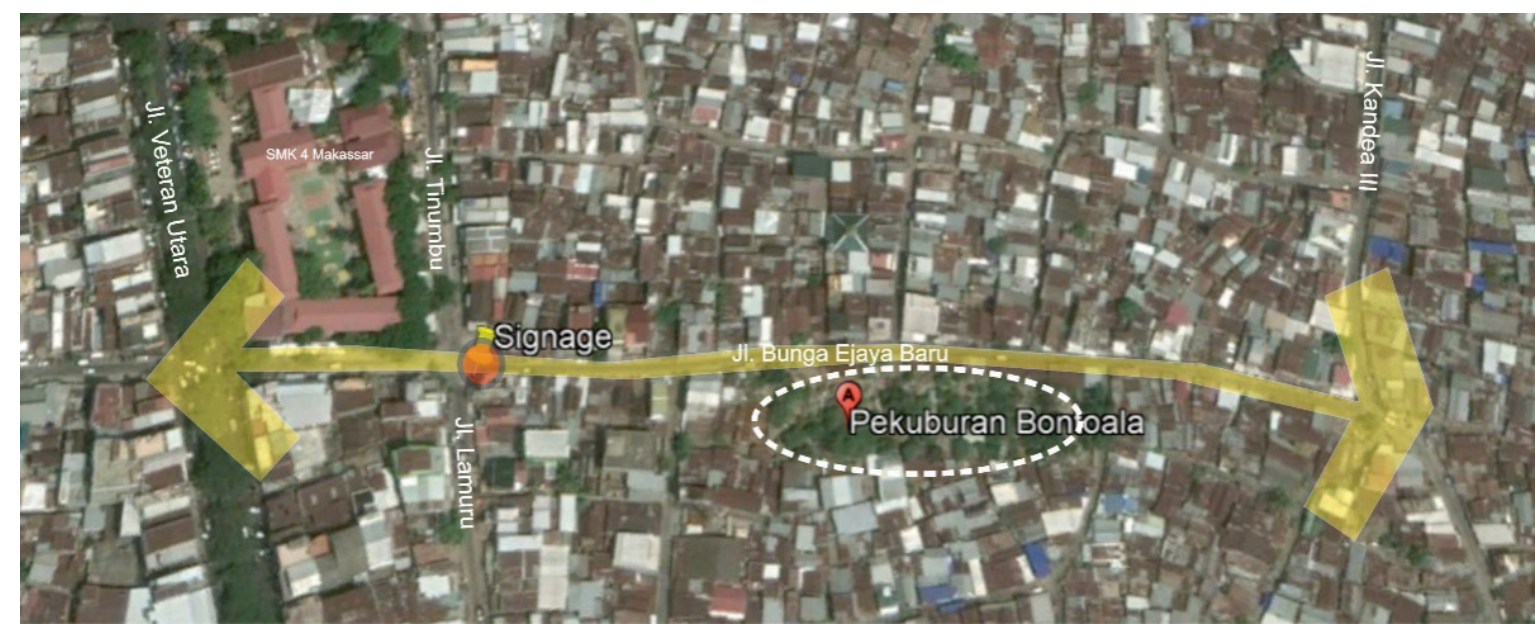

Gambar 7. Signage pada Node Menjadi Identitas Baru pada Simpul Koridor 
serta sosial seperti Vietnam dan permasalahan lainnya pada tahun 1970an. Hal tersebut dimotivasi oleh rasa senasib dan kreativitas secara bertahap mereka membawa wayfinding ke abad 21 berdasarkan pengalaman desainer yang ada pada periode sebelumnya. Pada masa perang dingin 1960, para kritikus, pelajar, dan desainer merasa bahwa pertumbuhan kota yang semakin kompleks membutuhkan sebuah perancangan penunjuk arah. Ilmu ini kemudian disebut dengan desain signage atau sign system, environmental graphic design dan wayfinding. Seiring berjalannya waktu, beberapa individu dan perusahaan mulai fokus dalam mengembangkan dan merancang signage.

Selanjutnya dilakukan diskusi dengan membuat sketsa beberapa contoh alternatif desain signage yang dapat dipilih oleh masyarakat setempat. Alternatif desain mencakup bentukbentuk geometris serta pemilihan warna yang memungkinkan (Gambar 9 dan 10). Mengingat beberapa warna tidak dapat dipilih karena serupa dengan rambu-rambu lalu lintas misalnya warna kuning, warna putih, atau warna biru. Diskusi tersebut menghasilkan keputusan untuk membuat signage yang bernuansa Islami. Nuansa Islami ditonjolkan pada tampilan visual warna menggunakan hijau sebagai simbol keislaman sehingga sesuai dengan image sebagai elemen petunjuk arah menuju ke Kawasan Pemakaman Islam Bontoala. Bentuk signage menggunakan bentuk geometri persegi panjang, memberi kesan sederhana, mudah diingat, dan terkesan ringan. Hal ini sesuai dengan Pernyataan Wijayanti (2019) bahwa desain signage perlu memperhatikan standar pemilihan warna sesuai dengan peraturan namun juga tetap dapat diinovasi guna menambah citra kota. Signage yang dibuat merupakan directional sign yang digunakan untuk penunjuk arah lokasi yang akan dituju pengunjung.

Menurut Surya (2016) secara umum tandatanda dapat diklasifikasikan sesuai dengan fungsi diantaranya (1) Informasi seperti peta, direktori atau tanda-tanda instruksional, (2) Arah seperti lokasi layanan, fasilitas, ruang fungsional, seperti posting tanda atau arah panah, (3) Identifikasi seperti nomor kamar, tanda toilet dan sebutan lantai, dan (4) Keselamatan dan peraturan, seperti tanda peringatan, rambu lalu lintas, tanda keluar, tanda tanda menyampaikan aturan, dan peraturan. Jenis signage yang digunakan pada lokasi adalah free-standing sign karena penempatannya digunakan untuk koridor jalan (outdoor). Dengan konsep demikian diharapkan menjadi salah satu upaya untuk membangun identitas visual yang dapat menciptakan karakteristik khas yang kuat pada kawasan dan mampu meningkatkan awareness pada pengunjung apalagi bila ditempatkan sesuai standarisasi sehingga mudah menemukan lokasi yang dituju (Maymun \& Swasty, 2018).

Tim Pelaksana Pengabdian memberikan dua alternatif desain signage (Gambar 9 dan Gambar 10) yang paling sesuai dengan kriteriakriteria yang disebutkan sebelumnya antara lain nuansa Islami, warna yang berbeda dari rambu-rambu lalu lintas, dan bentuk geometris sederhana, mudah diingat, dan terkesan ringan.
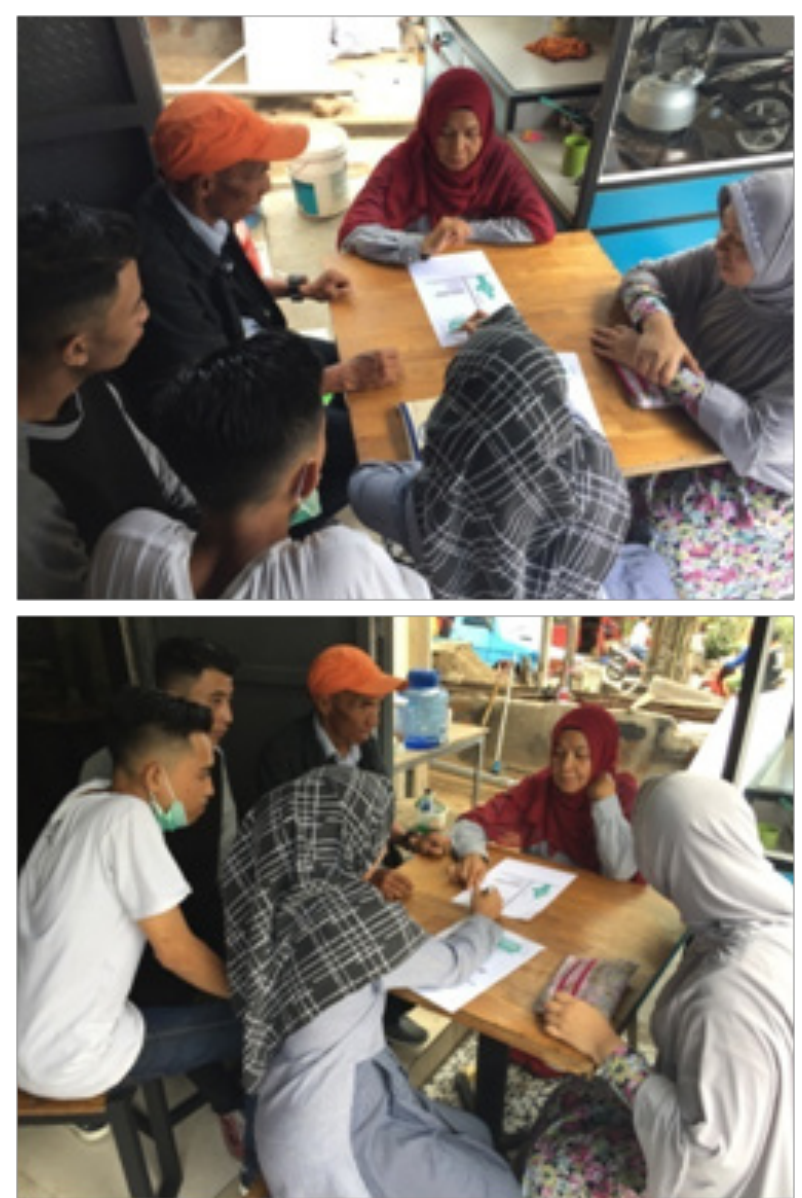

Gambar 8. Diskusi Konsep Desain Signage 


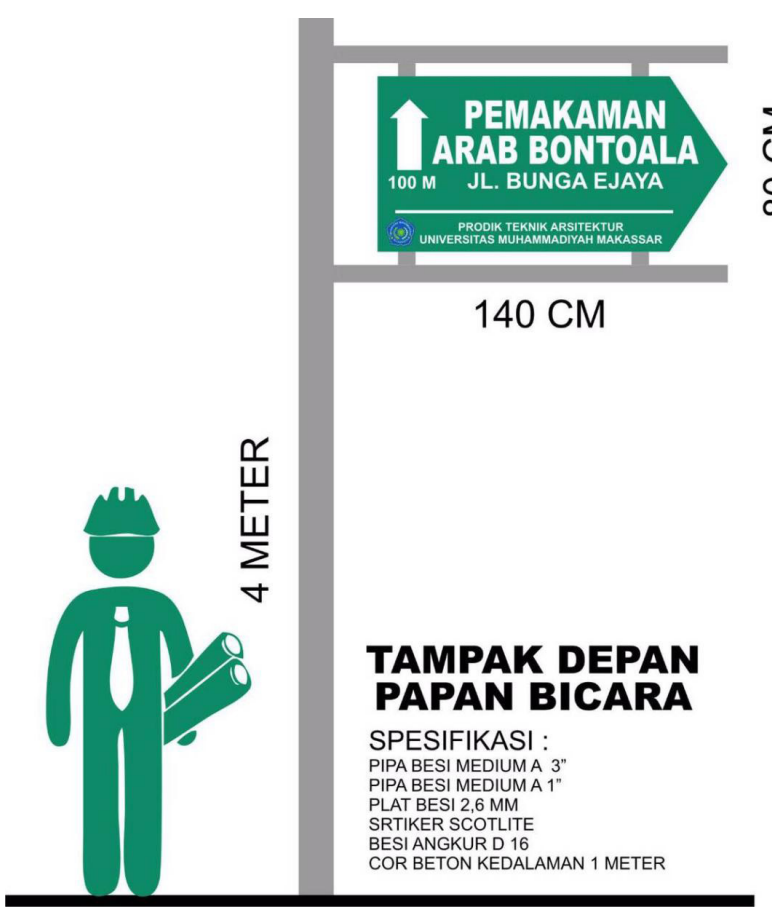

Gambar 9. Design Signage Alternatif 1

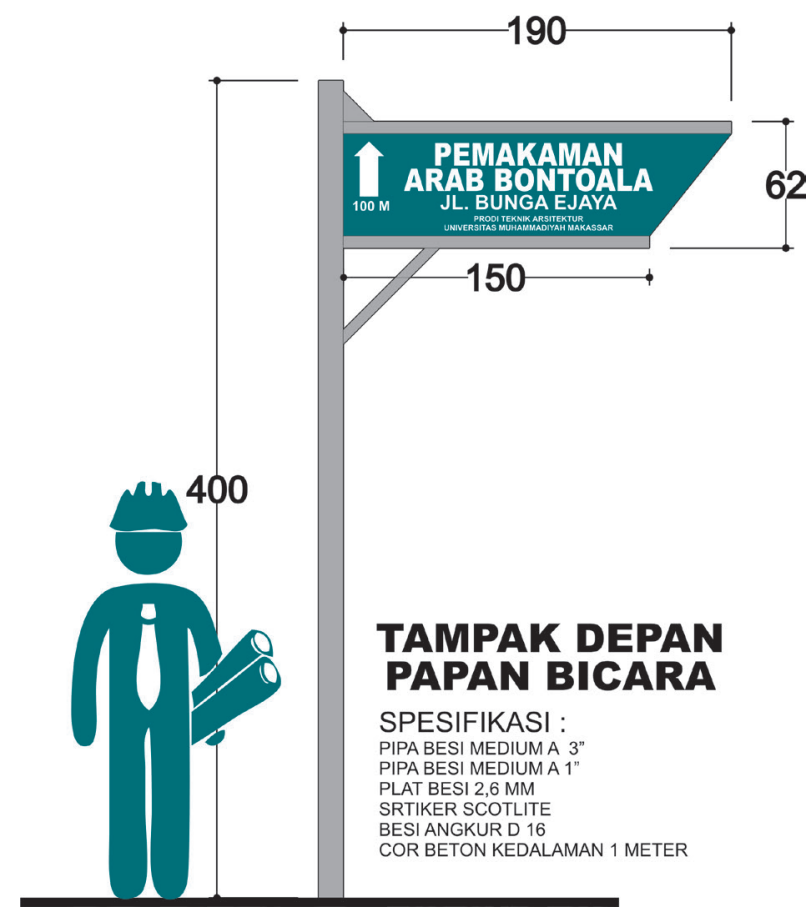

Gambar 10. Desain Signage Alternatif 2

Dari kedua alternatif desain signage yang diberikan oleh tim pelaksana pengabdian, lalu diadakan diskusi mengenai alternatif desain mana yang akan digunakan. Hasil diskusi disekapakati bahwa desain signage yang terpilih adalah desain signage alternatif 2 dengan pertimbangan bahwa desain ini terlihat
Tabel 1. Konsep Visual Desain Signage

\begin{tabular}{lll}
\hline \multicolumn{1}{c}{ Konsep } & \multicolumn{2}{c}{ Keterangan } \\
\hline Tema & Nuansa Islami & \\
\hline Bentuk & $\begin{array}{l}\text { Perpaduan segitiga dan persegi } \\
\text { panjang (panah penunjuk arah) }\end{array}$ \\
\hline Tipografi & $\begin{array}{l}\text { Tipografi yang digunakan } \\
\text { adalah jenis dekoratif , terdapat }\end{array}$ \\
& $\begin{array}{l}\text { logo kampus Universitas } \\
\text { Muhammadiyah dan penunjuk } \\
\end{array}$ & \\
\hline Warna & Hijau (papan signage) & kombinasi \\
& abu-abu (tiang) \\
\hline Material & Plat besi, pipa besi \\
\hline
\end{tabular}

lebih simpel, praktis, ringan, dan sekaligus kuat karena papan informasi tulisan langsung menyatu dengan tiang besi penopangnya. Berbeda dengan desain signage alternatif 1 yang menurut mereka mudah dilepas oleh orang yang tidak bertanggung jawab (rawan vandalism).

Konsep visual yang akan diimplementasikan pada desain signage Pemakaman Arab Bontoala memperhatikan aspek warna, tipografi, material dan jenis pemasangan yang dijabarkan dalam tabel 1.

\section{Persiapan Alat dan Bahan}

Tenaga kerja terdiri atas beberapa tukang dan masyarakat setempat. Alat-alat yang digunakan terdiri atas meteran, kabel stop kontak, gurinda, travo las, kawat las, batu pemotong besi, batu penghalus besi, kertas gosok, sekop, linggis, dan kuas cat berdiameter 2 inch. Bahan-bahan yang digunakan terdiri atas pipa besi berdiameter 1 dan 3 inch, plat besi 2.6 $\mathrm{mm}$, besi beton diameter $16 \mathrm{~cm}$, semen, pasir, batu kerikil,air bersih, wadah untuk mencampur, bambu untuk menopang, cat dasar, cat besi warna abu silver, cat besi warna hijau, dan sticker scotlite. Cat besi yang dipilih harus mengandung anti karat dan tahan panas. Pekerja terdiri atas kepala tukang, tukang las, dan buruh.

Beberapa material yang dapat digunakan dalam merancang signage diantaranya adalah metal, kaca, kayu, batu, banner, plastik, dan composite. Masing-masing memiliki pertimbangan dalam proses pengerjaan dan pemeliharaanya. Material metal terdiri dari 
aluminium, stainless steel, perunggu, dan kuningan digunakan secara umum dalam pembuatan signage, karena mudah dibentuk dan tahan lama. Kaca sering diaplikasikan untuk interior dan eksterior, karena bagian belakang dapat ditambahkan aksesoris lampu baik pada kacajenislaminated, tempered, fritted, borosilikat, float, maupun low emissitivity. Material kayu dibanding material lainnya kurang tahan lama terutama untuk lokasi dengan curah hujan tinggi dan dapat menua seiring berjalannya waktu. Batu dapat digunakan sebagai bagian atau dasar signage, memberikan kesan menyatu pada suatu latar belakang atau arsitektur dengan proses carving, sandblasting atau water-jet cutting. Jenis batu yang diaplikasikan bisa berupa slate, sandstone, marmer, batu kapur, maupun granit. Banner dapat digunakan untuk pameran temporer atau outdoor signage terbuat dari kain, plastik, atau material lentur lainnya. Banner dapat berupa vinyl, nilon, tyvek, poplin, dan dakron. Selain itu material lain untuk signage plastik yang dapat dicetak atau disablon, serta material composite yang permukaannya dapat dicat, dicetak ataupun langsung digunakan.

\section{Tahap Perakitan dan Pemasangan Signage}

Pertama-tama dilakukan pengukuran pipa besi dan plat besi agar sesuai dengan desain signage yang direncanakan oleh tukang las secara mandiri. Setelah diukur, pipa besi serta plat besi tersebut dipotong dengan menggunakan gurinda sesuai ukuran dari spesifikasi desain. Hasil potongan pipa besi dan plat besi kemudian dirangkai menjadi satu kesatuan utuh dengan menggunakan teknik las. Setelah dilakukan pengelasan, lalu dihaluskan dengan menggunakan kertas gosok (Gambar 11). Selanjutnya, rangkaian signage tersebut dicat menggunakan cat dasar. Setelah kering, dicat menggunakan cat besi warna abu-silver, dan dilakukan pengecekan ulang kesesuaian ukuran tiang signage dengan desain (Gambar 12). Hasil signage tampak bagian penempatan tulisan informasi dicat warna hijau (Gambar 13) dan akan dipasangkan sticker scotlite yang berisi keterangan atau informasi yang ditampilkan oleh signage.

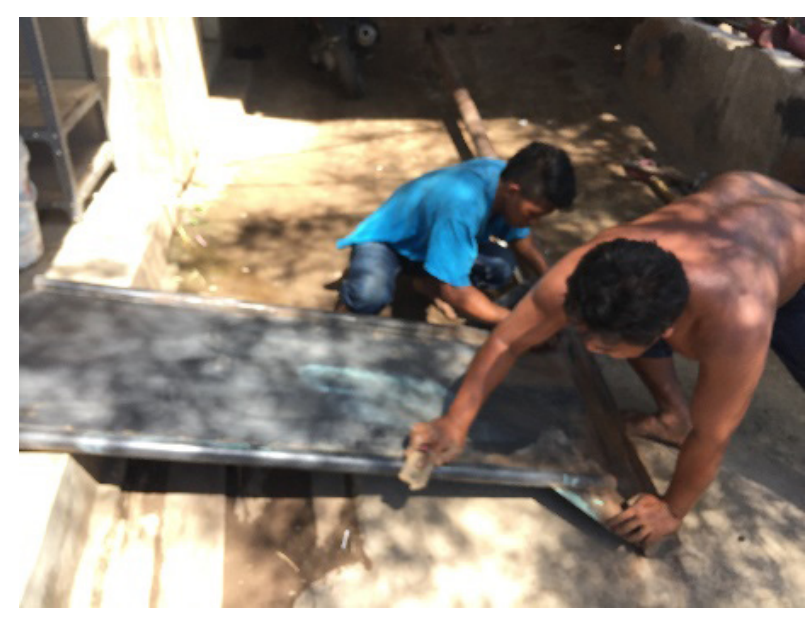

Gambar 11. Tahap Penghalusan Papan Signage

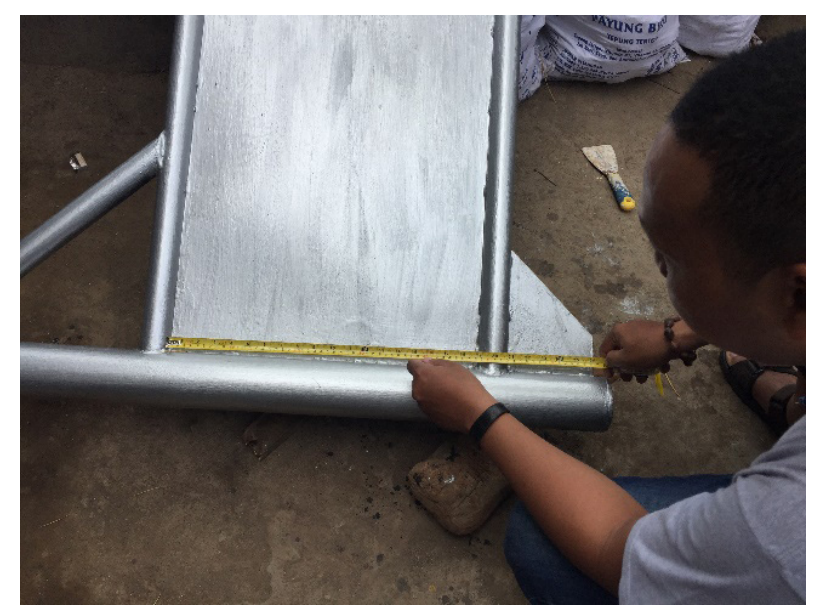

Gambar 12. Tahap Pengecekan Ukuran

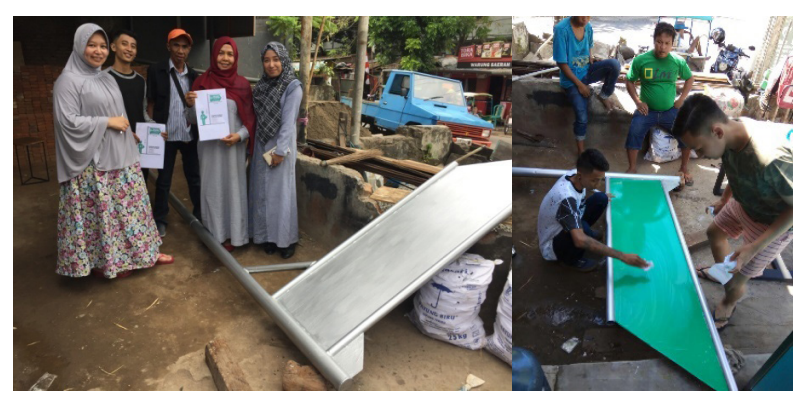

Gambar 13. Tahap Pemasangan Sticker Scotlight

Tahap pemasangan serta finishing visual satu buah signage dengan ukuran dan spesifikasi sesuai desain signage alternatif 2 (Gambar 10) dilakukan secara bersama-sama antara tim pelaksana pengabdian dengan masyarakat setempat dan Ketua RT. Pada tahap pemasangan, juga memperhatikan ketinggian signage dan arah datang cahaya juga layout. Sesuai kesepakatan sebelumnya, signage dipasang di node Jalan Bunga Ejaya, Jalan Tinumbu, dan 
Jalan Lamuru, dengan harapan agar signage dapat terbaca dengan jelas dan mudah dipahami masyarakat. Ketinggian dimensi perletakan signage yang sesuai dengan segala keadaan kondisi pengunjung, baik pengunjung yang memiliki keterbatasan seperti memakai kursi roda, keterbatasan dalam melihat terutama manula (Ruki \& Nediari, 2014).

Tahap pemasangan signage diawali dengan penggalian tanah menggunakan sekop dan linggis pada titik yang telah ditentukan dengan kedalaman kurang lebih 1 meter, serta disiapkan juga pencampuran bahan beton menggunakan semen, pasir, dan batu kerikil dengan perbandingan 1:2:3 serta besi beton diameter $16 \mathrm{~cm}$. Selanjutnya tiang signage dimasukkan ke dalam lubang hasil galian yang tersedia dan dalam posisi berdiri dengan bantuan bambu penopang, serta dituangkan bahan campuran adukan beton yang telah disiapkan sebelumnya. Tiang bambu penopang tetap digunakan sampai campuran adukan beton kering dan mengeras, hingga signage dapat dilepas berdiri sendiri.

\section{Monitoring dan Evaluasi}

Setelah seluruh kegiatan selesai, tim pelaksana pengabdian melakukan monitoring dan evaluasi secara sederhana terhadap signage yang telah terpasang. Untuk mengamati kondisi fisik signage serta perilaku masyarakat setempat dengan kehadiran signage tersebut, serta mengevaluasi peranan dan bentuk desain signage yang dapat menjadi masukan maupun perbaikan bagi perencanaan di kemudian hari. Pengamatan kondisi fisik meliputi keutuhan rangkaian signage yang bebas dari aksi vandalism maupun anarkisme. Pengamatan perilaku masyarakat setempat terkait fungsi signage dalam kehidupan sehari-hari masyarakat sekitar.

Hasil dari monitoring dan evaluasi ini memperlihatkan bahwa koridor Jalan Bunga Ejaya sebelum kegiatan PKM ini, belum terdapat elemen penanda menuju Pemakaman Arab Bontoala. Setelah kegiatan PKM tampak terlihat perubahan dengan adanya signage yang terpasang masih dalam keadaan utuh dan terawat hingga saat ini, walaupun telah mencapai
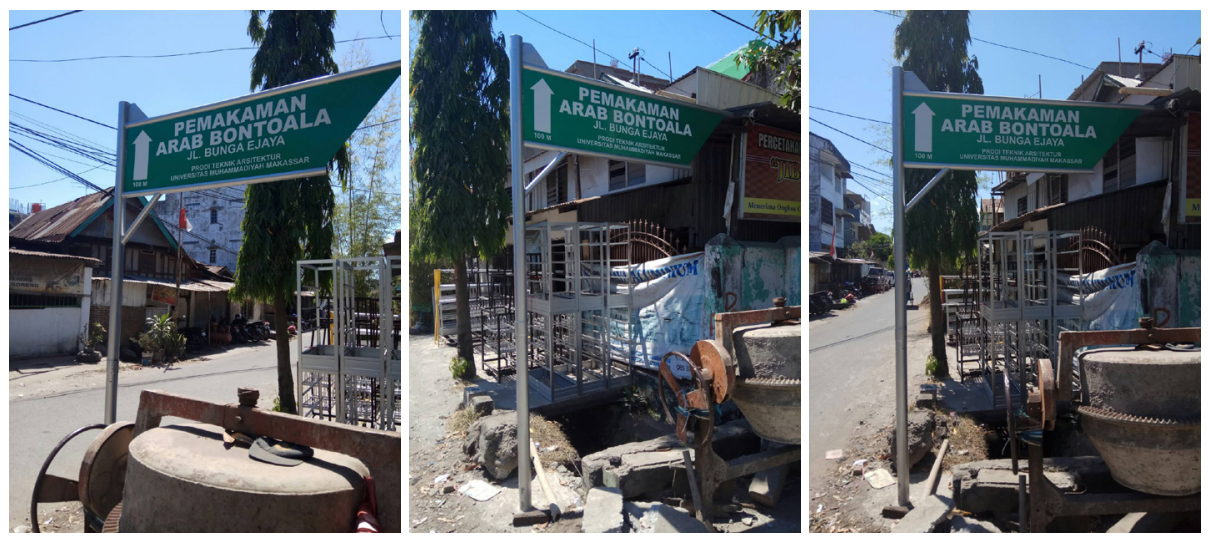

Gambar 14. Tahap Pemasangan Signage
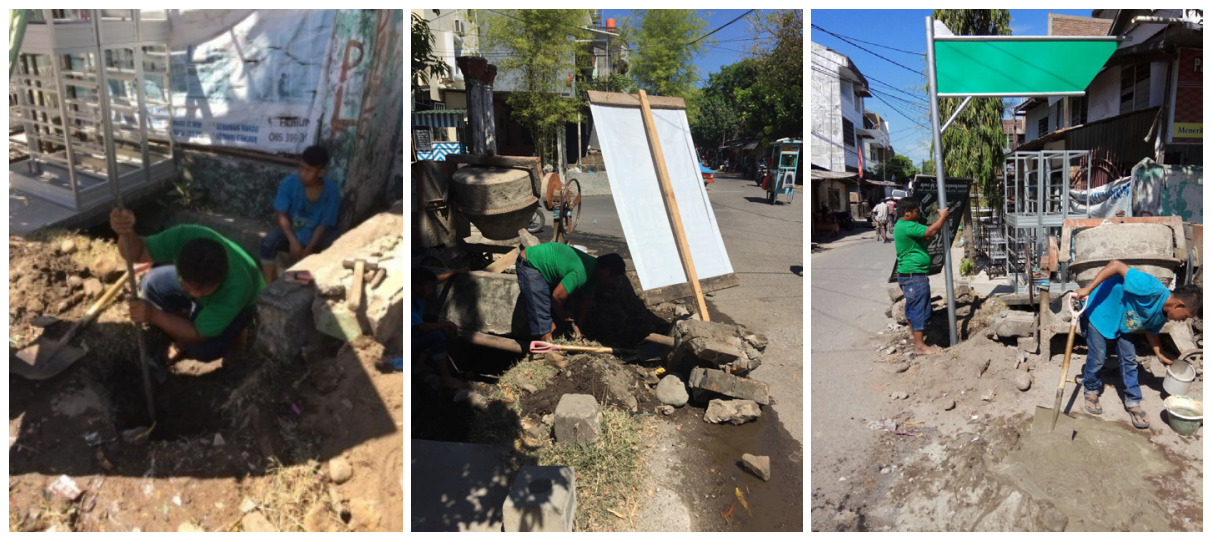

Gambar 15. Signage Telah Terpasang pada Node 
usia tiga tahun. Keberadaan signage tidak hanya berfungsi sebagai penanda teritorial wilayah Pemakaman Arab Bontoala, tetapi juga berfungsi untuk menentukan titik lokasi bagi jasa layanan pengantaran baik ekspedisi maupun aplikasi driver online, sehingga semakin memudahkan masyarakat dalam menggunakan kedua layanan tersebut. Kedepannya diharapkan bahwa bentuk desain signage masih dapat dikembangkan lebih lanjut, misalnya menambah titik jumlah pemasangan dan ragam jenis informasi yang tertuang dalam signage agar menjadi satu kesatuan sebagai penanda wilayah yang lebih luas, atau pemasangan map direction.

\section{SIMPULAN}

Penataan yang dilakukan merupakan bentuk pengabdian masyarakat sebagai wujud Tri Dharma Perguruan Tinggi dalam hal pembuatan directional sign ini merupakan salah satu papan informasi yang membantu pengunjung atau pengguna jalan yang akan berkunjung ke Pemakaman Arab Bontoala. Selain itu, signage ini diharapkan dapat menjadi sarana efektif yang mengarahkan pengunjung menuju ke lokasi tersebut. Hasil monitoring menunjukkan bahwa signage yang telah dibuat juga menjadi identitas lokasi yang dapat membantu driver online untuk menemukan tempat lebih cepat dan mudah di sekitar lokasi tersebut. Adapun saran dari kegiatan pengabdian ini yaitu penataan visual signage dapat dilakukan dengan menghubungkan beberapa visual signage melalui axis atau sumbu-sumbu. Selain itu, pada kawasan masih diperlukan adanya Map Direction yang penempatannya dapat berdampingan dengan signage yang telah dibuat.

\section{UCAPAN TERIMA KASIH}

Tim Pelaksana Pengabdian mengucapkan terima kasih kepada Lembaga Penelitian Pengembangan dan Pengabdian (LP3M) Universitas Muhammadiyah Makassar atas bantuan pendanaan berdasarkan Surat Penugasan Pengabdian kepada Masyarakat N o. 0109 / KO N T R - P E N L / P E N G A B D / VIII/1438/2017 dalam rangka pelaksanaan Program Pengabdian kepada Masyarakat Tahun Anggaran 2017.

\section{DAFTAR PUSTAKA}

Ahmad, A. (2013). Studi Perancangan Identitas Visual Wilayah Karimunjawa. Jurnal Humaniora, 4(1), 567-579.

Hanifunisa, A., Swasty, W. (2020). Signage Informatif dan Interaktif pada The Heritage Palace Kota Surakarta Jawa Tengah. Jurnal Bahasa Rupa, 3(2), 95-103.

Maymun, A.Z., Swasty, W. (2018). Identitas Visual dan Penerapannya pada Signage untuk Kawasan Wisata Edukasi. Serat Rupa Journal of Design, 2(1), 1-13.

Nasruddin \& Marpaung, B.O.Y. (2018). Penataan Tata Informasi sebagai Penanda Visual Kawasan di Koridor Jamin Ginting Pancur Batu. Jurnal Arsitektur dan PerKotaan “KORIDOR”, 9(1), 99-105.

Puspitasari, D.G., \& Darmawan, J. (2013). Signage dan Penerapannya: Lingkungan Jalan Raya Tol Bintaro. Jurnal Humaniora, 4(1), 475-490.

Prastomo, Dicky. (2018). Wayfinding sebagai Solusi Petunjuk Arah di Zona Wisata Ziarah Desa Gunung Pring Muntilan. Jurnal TESA, XIII(1), 55-68.

Ruki, U.A., Nediari, A. (2014). Penerapan Tipografi dalam Sistem Signage pada Interior Ruang Publik. Jurnal Humaniora, 5(2), 822-832.

Situmorang, R.S., Swasty, W. (2016). Signage and Wayfinding Design of DR.H. Kumpulan Pane Regional General Hospital in Tebing Tinggi North Sumatra. Journal of Vicual Communication Design, 1(1), 52-69. 
Surya, G.G. (2016). Perancangan Map Direction dan Signage di Pulau Untung Jawa Guna Memfasilitasi Wisatawan. Jurnal Abdimas, 3(1), 105-122.

Taufiq, S.A., \& Wulandari, R. (2016). Efektivitas Lokasi Penempatan Papan Petunjuk (Signage System) pada Lobby Stasiun Kereta Api Bandung. Jurnal IDEALOG, 1(1), 49-62.

Wijayanti, E.N. (2019). Kajian Tipologi Perletakan dan Desain Signage sebagai Kebutuhan Kota Pelajar dan Wisata (Studi Kasus: Kecamatan Gondokusuman dan Jetis Kota Yogyakarta). 3 Arsitektur dan Keseharian: Keterampilan Lokal, Teknologi Konstruksi, Tektonika dan Pengalaman Meruan, 216-225.

Zubair, M. (2011). Makna dan Fungsi Inskripsi pada Makam Lajangiru di Bontoala Makassar (Studi Arkeo-epigrafi). Jurnal Al Qalam, 17(1), 59-70. 